\title{
PRDM3 attenuates pancreatitis and pancreatic tumorigenesis by regulating inflammatory response
}

Jie Ye ${ }^{1,2}$, Anpei Huang ${ }^{3}$, Haitao Wang $\mathbb{0}^{1,4}$, Anni M. Y. Zhang ${ }^{5}$, Xiaojun Huang ${ }^{1,2}$, Qingping Lan ${ }^{1,2}$, Tomohiko Sato ${ }^{6}$, Susumu Goyama ${ }^{6}$, Mineo Kurokawa ${ }^{6}$, Chuxia Deng ${ }^{1,2}$, Maike Sander ${ }^{7}$, David F. Schaeffer ${ }^{8}$, Wen Li ${ }^{3}$, Janel L. Kopp ${ }^{5}$ and Ruiyu Xie (B) ${ }^{1,2}$

\begin{abstract}
Pancreatic ductal adenocarcinoma (PDAC) is associated with metaplastic changes in the pancreas but the transcriptional program underlying these changes is incompletely understood. The zinc finger transcription factor, PRDM3, is lowly expressed in normal pancreatic acini and its expression increases during tumorigenesis. Although PRDM3 promotes proliferation and migration of PDAC cell lines, the role of PRDM3 during tumor initiation from pancreatic acinar cells in vivo is unclear. In this study, we showed that high levels of PRDM3 expression in human pancreas was associated with pancreatitis, and well-differentiated but not poorly differentiated carcinoma. We examined PRDM3 function in pancreatic acinar cells during tumor formation and pancreatitis by inactivating Prdm3 using a conditional allele (Ptfla ${ }^{\text {CreER. }}$ Prdm $3^{\text {floxflox }}$ mice) in the context of oncogenic Kras expression and supraphysiological cerulein injections, respectively. In Prdm3-deficient mice, Kras ${ }^{G 12 D}$-driven preneoplastic lesions were more abundant and progressed to high-grade precancerous lesions more rapidly. This is consistent with our observations that low levels of PRDM3 in human PDAC was correlated significantly with poorer survival in patient. Moreover, loss of Prdm3 in acinar cells elevated exocrine injury, enhanced immune cell activation and infiltration, and greatly increased acinar-to-ductal cell reprogramming upon cerulein-induced pancreatitis. Whole transcriptome analyses of Prdm3 knockout acini revealed that pathways involved in inflammatory response and Hif-1 signaling were significantly upregulated in Prdm3-depleted acinar cells. Taken together, our results suggest that Prdm3 favors the maintenance of acinar cell homeostasis through modulation of their response to inflammation and oncogenic Kras activation, and thus plays a previously unexpected suppressive role during PDAC initiation.
\end{abstract}

\section{Introduction}

Pancreatic ductal adenocarcinoma (PDAC) is the most common malignancy in pancreas and the third leading cause of cancer-related deaths in US ${ }^{1}$. Emerging evidence

\footnotetext{
Correspondence: Wen Li (liwen@mail.sysu.edu.cn) or Janel L. Kopp (Janel. kopp@ubc.ca) or Ruiyu Xie (ruiyuxie@um.edu.mo)

${ }^{1}$ Cancer Centre, Faculty of Health Sciences, University of Macau, 999078 Macau SAR, China

${ }^{2}$ Institute of Translational Medicine, Faculty of Health of Sciences, University of Macau, 999078 Macau SAR, China

Full list of author information is available at the end of the article

These authors contributed equally: Jie Ye, Anpei Huang

Edited by A. Stephanou
}

suggests that pancreatic acinar cells can acquire ductal cell-like characteristics and downregulate genes maintaining acinar cell identify, also known as acinar-to-ductal metaplasia (ADM). This process is reversible because once the injury is resolved the acinar cell-derived ductallike cells can revert back to acinar cells ${ }^{2,3}$. However, in the presence of additional stresses, such as a Kras ${ }^{G 12 D}$ mutation, ADM cannot be reversed and cells are "locked" into a transdifferentiated state before converting to precancerous pancreatic intraepithelial neoplasia (PanIN) lesions and subsequently invasive $\mathrm{PDAC}^{4-6}$. In mice, pancreatic tumorigenesis is dramatically hastened by the

\section{(c) The Author(s) 2020}

(c) (i) Open Access This article is licensed under a Creative Commons Attribution 4.0 International License, which permits use, sharing, adaptation, distribution and reproduction cc) in any medium or format, as long as you give appropriate credit to the original author(s) and the source, provide a link to the Creative Commons license, and indicate if changes were made. The images or other third party material in this article are included in the article's Creative Commons license, unless indicated otherwise in a credit line to the material. If material is not included in the article's Creative Commons license and your intended use is not permitted by statutory regulation or exceeds the permitted use, you will need to obtain permission directly from the copyright holder. To view a copy of this license, visit http://creativecommons.org/licenses/by/4.0/. 
presence of pancreatitis ${ }^{7,8}$, while, in humans, induction of chronic inflammation is a common character in many known risk factors for pancreatic cancer including diabetes, pancreatitis, alcohol consumption and tobacco use $^{9}$. However, the complete transcriptional program that regulates the interconversion of acinar cells to ductal-like cells and vice versa, and the role of these events in the context of tumorigenesis are still unclear.

PRDM3 is a nuclear transcription factor involved in many biological processes including hematopoiesis, development, cell differentiation and apoptosis ${ }^{10}$. PRDM3 belongs to the positive regulatory domain (PRDM) family proteins, which are characterized by an $\mathrm{N}$-terminal $\mathrm{PR}$ (PRDI-BF1-RIZ1 homologous) domain followed by an array of $\mathrm{C} 2 \mathrm{H} 2$ zinc finger motifs for sequence-specific DNA binding and a C-terminal binding protein (CtBP)binding domain for protein-protein interactions ${ }^{11}$. PRDM3 is necessary for the maintenance of hematopoietic stem cells ${ }^{12,13}$. A recent study has reported that PRDM3 is weakly expressed in normal pancreatic acinar cells and upregulated in many PDAC precursor lesions and PDAC ${ }^{14}$. Using siRNA-mediated knockdown of PRDM3 in PK-8 pancreatic cancer cells, Tanaka and colleagues also showed that PRDM3 promotes pancreatic cancer cell proliferation and migration through the inhibition of a KRAS suppressor miR-96 ${ }^{14}$. Despite this characterization of the effects of PRDM3 inhibition in pancreatic tumor cells ex vivo, the role of PRDM3 during tumor initiation from acinar cells in vivo is unclear.

Here, we used a CreER-inducible mouse model to genetically delete Prdm3 specifically in adult acinar cells to examine the functional role of PRDM3 in pancreatic carcinogenesis. Our results show that Prdm3 deficiency potentiates inflammation, promotes tumor initiation and dramatically accelerates malignant progression, which is consistent with our findings indicating that PRDM3 loss is significantly associated with poorer survival in patients with PDAC. We further demonstrate that PRDM3 is important to suppress the expression of genes involved in inflammatory response in pancreatic acinar cells. These findings suggest an inhibitory role of PRDM3 in pancreatic tumorigenesis. Future development of drugs that target PRDM3 might yield novel approaches to benefit the treatment of PDAC.

\section{Results}

PRDM3 is upregulated in pancreatitis, as well as welldifferentiated PDAC and its high expression is associated with better survival in patients with PDAC

We first characterized the expression of PRDM3 and its relevance to pancreatic cancer prognosis by analyzing a cohort of 94 patients who were diagnosed with PDAC and received surgical resection without preoperative chemotherapy. We found that PRDM3 was strongly expressed in precancerous PanIN lesions (Fig. 1c-c') and well-differentiated PDAC from patients (Fig. 1d-d'), while moderately to poorly differentiated cancer cells showed little to no staining of PRDM3 (Fig. 1e-e', f-f', Table 1). Our observation of heterogeneous expression of PRDM3 in PDAC was supported by a recent study demonstrating that PRDM3 is selectively expressed in low-grade PDAC cells featuring differentiated epithelia, but not high-grade cells showing fibroblastoid morphology ${ }^{15}$. We performed subsequent overall survival and disease-free survival analyses with these 94 PDAC patients and found that patients with high levels of PRDM3 lived significantly longer than those with low levels of PRDM3 (Overall survival: 16.0 months vs. 9.3 months; Disease-free survival: 12.4 months vs. 7.4 months) (Fig. $1 \mathrm{~g}$ ). Our clinical relevance analysis clearly revealed that a better survival in patient with PDAC was associated with high levels of PRDM3 expression, but not with age, gender, tumor size, location, TNM (tumor-node-metastasis), or CA19-9 (Table 1). Given that pancreatitis is a well-described risk factor for PDAC development, we also analyzed pancreatic tissue from 22 patients with chronic pancreatitis. We found a dramatic increase of PRDM3 protein levels in inflamed tissues compared with normal pancreas (Fig. 1a-a', b-b'; Supplementary Table 1). Similarly, administration of supraphysiologic concentrations of a cholecystokinin ortholog, cerulein, in mice resulted in acute pancreatitis and Prdm3 upregulation in murine acinar cells (Supplementary Fig. 1a). Consistent with findings from previous reports ${ }^{14}$, we also observed strong expression of Prdm3 in the precursor lesions of PDAC including ADM, low-grade PanINs, and high-grade PanINs found in pancreata from mice expressing oncogenic Kras in pancreatic acinar cells (Ptf1a ${ }^{\text {CreER }}$; Kras ${ }^{G 12 D}$ ) (Supplementary Fig. 1b). Together, our results demonstrated that elevated levels of PRDM3 are associated with inflamed pancreatic epithelia and well-differentiated pancreatic lesions, while low levels of PRDM3 are associated with poorly differentiated carcinoma and a worse prognostic outcome in patients with PDAC.

\section{Ablation of Prdm3 enhances Kras ${ }^{\mathrm{G} 12 \mathrm{D}}$-stimulated PDAC initiation and progression}

To determine whether Prdm3 is functionally important for pancreatic carcinogenesis in vivo, we applied a genetic strategy to induce expression of oncogenic $\mathrm{Kras}^{G 12 D}$ and deletion of Prdm3 in adult acinar cells, simultaneously. Cre-mediated recombination was induced in pancreatic acinar cells using the tamoxifen-inducible $P t f 1 a^{C r e E R}$ allele $^{16}$. The Mds1 and Evi1 complex locus (Mecom) encodes a full-length isoform of Prdm3, and a shorter isoform lacking the N-terminus PR domain. We therefore used a Prdm $3^{\text {flox }}$ mouse which harbors two LoxP sites flanking exon 4, the first shared exon in the long- and 

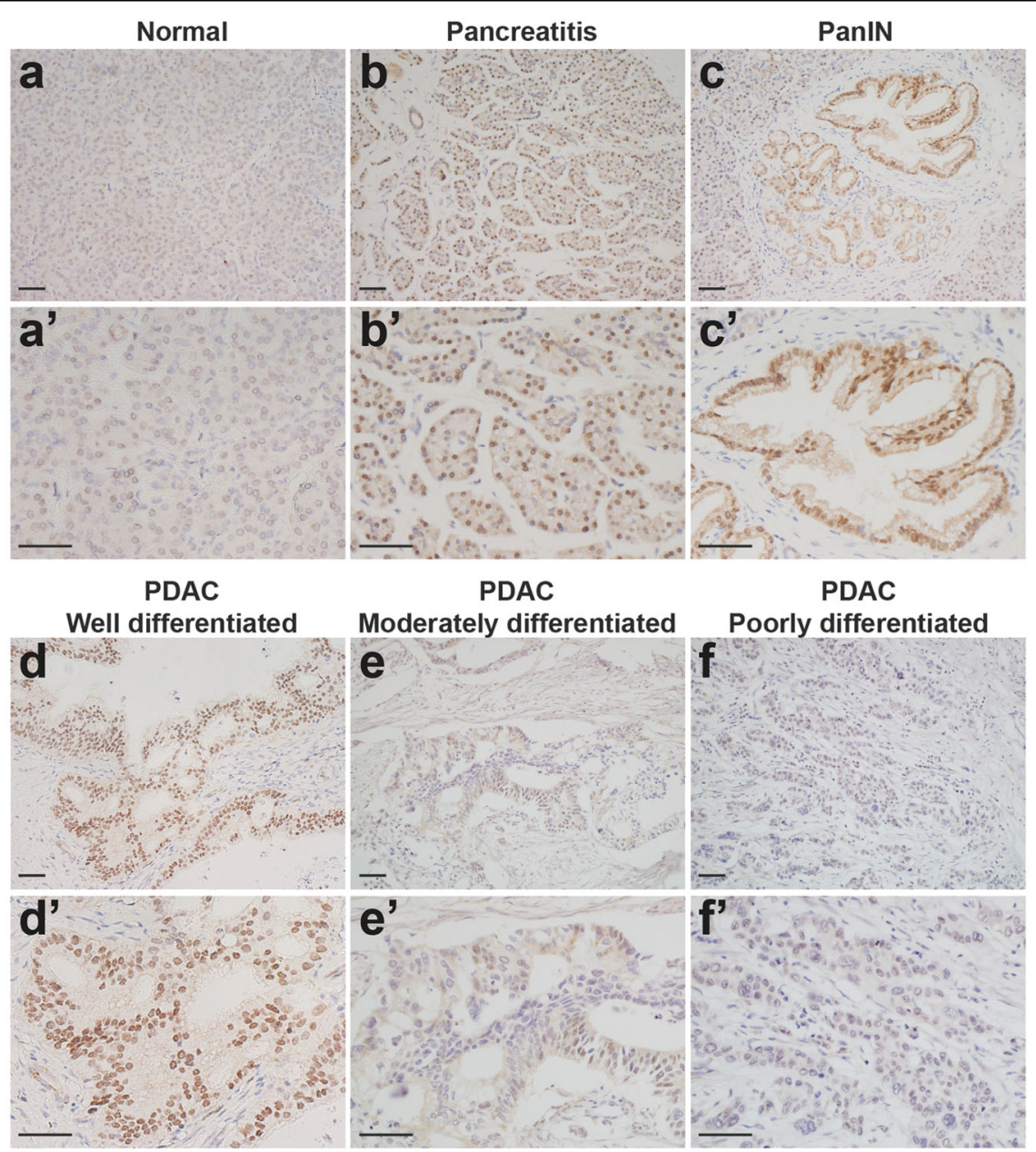

PDAC
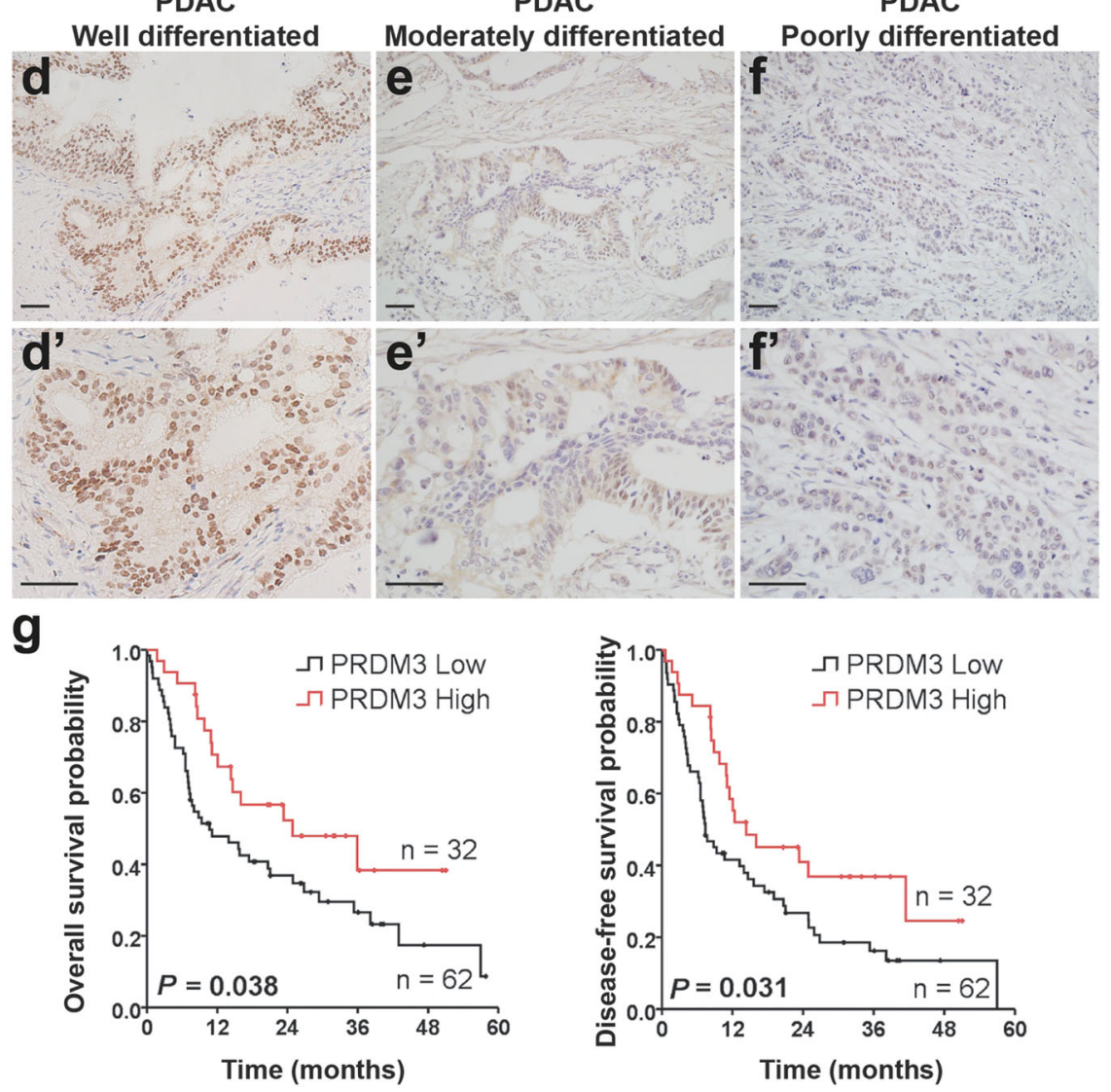

Fig. 1 Weak PRDM3 expression is associated with poorly differentiated tumors and a worse prognostic outcome in patients with PDAC. Prdm3 immunostaining in normal pancreatic tissue (a and $\mathbf{a}^{\prime}$ ), pancreatitis ( $\mathbf{b}$ and $\mathbf{b}^{\prime}$ ), PanIN (c and $\left.\mathbf{c}^{\prime}\right)$, well-differentiated (d and $\mathbf{d}^{\prime}$ ), moderately differentiated (e and $\mathbf{e}^{\prime}$ ), and poorly differentiated (f and $\mathbf{f}^{\prime}$ ) PDAC. $\mathbf{g}$ The overall survival probability and disease-free survival probability were compared between low $(n=32$, staining index $\leq 6)$ and high $(n=62$, staining index $>6)$ levels of PRDM3 expression in a cohort of 94 PDAC patients after surgical resection. $p$-values were calculated based on log-rank test. Scale: $50 \mu \mathrm{m}$.

short-isoform of $\operatorname{Prdm} 3^{12}$, to completely eliminate $\operatorname{Prdm} 3$ in pancreatic acinar cells upon tamoxifen induced recombination. By combining the Kras ${ }^{L S L-G 12 D}$ allele $^{17}$ with the Ptfla CreER allele with/without the Prdm3 $3^{\text {flox }}$ allele, we generated control Ptf1a ${ }^{\text {CreER }} ; K_{r a s}{ }^{G 12 D}$
$\left(\operatorname{Kras}^{G 12 D}\right)$ mice, as well as Ptf1a ${ }^{\mathrm{CreER}} ; \mathrm{Kras}^{\mathrm{G12D}}$; Prdm3 ${ }^{\text {flox/flox }}\left(\right.$ Kras $^{\text {G12D }}$-Prdm3 $\left.{ }^{\Delta A c i n a r}\right)$ mice (Supplementary Fig. 2a).

To initiate recombination, we injected mice with tamoxifen at 4 to 5 weeks of age and analyzed pancreata at 
Table 1 Association between expression levels of PRDM3 and clinical relevance in patients with PDAC $(n=94)$.

\begin{tabular}{llll}
\hline Characteristics & Low & High & $p$-value $^{\mathrm{a}}$ \\
& $\begin{array}{l}\text { expression } \\
(n=62)\end{array}$ & $\begin{array}{l}\text { expression } \\
(n=32)\end{array}$ & \\
& & & \\
\hline
\end{tabular}

Histological grade

$<0.001$

Poorly differentiated

Moderately differentiated

Well differentiated

Survival ${ }^{\text {b }}$

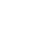

$\begin{array}{lll}\text { Alive } & 17 & 16 \\ \text { Death } & 45 & 16\end{array}$

Age (years)

$\begin{array}{lll}>60 & 24 & 19 \\ \leq 60 & 38 & 13\end{array}$

Gender

Female

Male

22

40

Tumor size $(\mathrm{cm})$

$\begin{array}{lll}\leq 2.0 & 10 & 8 \\ >2.0 & 52 & 24\end{array}$

Location

\begin{tabular}{|c|c|c|c|}
\hline Head & 50 & 23 & \\
\hline Body and tail & 12 & 9 & \\
\hline TNM $^{\mathrm{C}}$ & & 0.717 & \\
\hline I, II & 54 & 27 & \\
\hline III, IV & 8 & 5 & \\
\hline CA19-9 & & & 0.526 \\
\hline$\leq 35$ & 12 & 8 & \\
\hline$>35$ & 50 & 24 & \\
\hline
\end{tabular}

${ }^{\mathrm{a}} p$-values were based on $t$-test (two-sided). $p<0.05$ was considered as statistically significant.

${ }^{\mathrm{b}}$ All PDAC patients received surgical resection without preoperative chemotherapy; median follow-up was 12.1 months after surgical resection; median survival time for patients deceased was 8.0 months; median follow-up for patients alive was 26.4 months.

'The tumor-node-metastasis (TNM) stages were determined according to the 7th edition TNM classification of the American Joint Committee on Cancer. Bold values indicate a statistically significant difference with a $p$-value less than 0.05 .

4 weeks and 6 weeks post-injection (Fig. 2a). Comparison of Prdm3 expression in $K r a s^{G 12 D}-\operatorname{Prdm} 3^{\Delta A c i n a r}$ and Kras $^{G 12 D}$ mice after tamoxifen administration showed an almost complete loss of Prdm3 protein in $\mathrm{Kras}^{\mathrm{G12D}}$ Prdm3 $3^{\Delta \text { Acinar }}$ acinar cells (Supplementary Fig. 2b, top panel). Four weeks after tamoxifen-mediated recombination, small areas of ADM and occasional low-grade
PanINs were observed in the control Kras ${ }^{G 12 D}$ mice. In contrast, $K r a s^{G 12 D}-\operatorname{Prdm} 3^{\Delta A c i n a r}$ mice, with loss of Prdm3 in pancreatic acinar cells, exhibited more cuboidal to columnar duct-like structures with enlarged lumens (Supplementary Fig. 2b, bottom panel). Quantification of the number of PanINs revealed that preneoplastic lesions arising in $\mathrm{Kras}^{G 12 D}$-Prdm3 $3^{\Delta A c i n a r}$ mice increased significantly compared to Kras ${ }^{G 12 D}$ mice (Fig. 2b). More intriguingly, we observed 4 out of $5 \mathrm{Kras}^{\text {G12D }}$-Prdm3 ${ }^{\Delta A c i n a r}$ mice developed high-grade PanINs at 4 weeks posttamoxifen injection (Fig. 2c), while no high-grade lesions were found in $\mathrm{Kras}^{G 12 D}$ mice even at 3 months of age (data not shown). Consistent with these findings, at 6 weeks post-tamoxifen injection $\mathrm{Kras}^{G 12 D}$-Prdm $3^{\Delta \text { Acinar }}$ mice exhibited higher number of lesions with histological and molecular characteristics of PanINs indicated by the expression of Cytokeratin 19 (CK19) (Fig. 2d) and the present of acidic mucin content indicated by Mucin $5 \mathrm{AC}$ (Muc5AC) and Alcian blue staining (Supplementary Fig. 2c). Altogether, these data suggest that deletion of Prdm3 promotes PanIN formation in the presence of oncogenic Kras expression.

To further examine whether loss of Prdm3 promotes acinar to ductal transformation in the presence of mutant Kras, we isolated primary acinar cell clusters from 8week-old $\mathrm{Kras}^{G 12 D}$-Prdm3 ${ }^{\Delta A c i n a r}$ and $K r a s^{G 12 D}$ mice, respectively, and performed 3D Matrigel explant culture. In agreement with the histologic observations, Prdm3 deficiency led to a significant increase in earlier ADM evens within $48 \mathrm{~h}$ in culture, as quantified by counting the number of duct-like structures vs. the total number of cell clusters (Fig. 2e, f). Previous studies have demonstrated that $T g f-\alpha$ is upregulated in $\operatorname{Kras}^{G 12 D}$ pancreata ${ }^{18}$ and acts as a potent inducer for the transdifferentiation of acinar to ductal cells ${ }^{19,20}$. Therefore, we also tested if Prdm3 depletion impacts TGF- $\alpha$-induced in vitro ADM. Acinar cell explants derived from $\mathrm{Prdm} 3^{\Delta \text { Acinar }}$ mice transformed into duct-like structures within $30 \mathrm{~h}$ in culture with addition of TGF- $\alpha$ (Supplementary Fig. 2d, e). This acinar to ductal cyst conversion was almost undetected in explants derived from control (Ptf1a $\left.{ }^{C r e E R}\right)$ mice until $48 \mathrm{~h}$ in culture. Collectively, our data support that loss of Prdm3 accelerates ductal metaplasia.

We next examined whether loss of Prdm3 promotes neoplastic progression. To accelerate the formation of invasive lesions, we induced cerulein-mediated acute pancreatitis in cooperation with acinar-cell-specific activation of oncogenic Kras as previously described ${ }^{4}$. One week after tamoxifen administration, $\mathrm{Kras}^{G 12 D}$-Prdm $3^{\Delta \text { Acinar }}$ and $K \mathrm{ras}^{G 12 D}$ mice were injected hourly with $50 \mu \mathrm{g} / \mathrm{kg}$ cerulein over $6 \mathrm{~h}$ on alternating days. The pancreata were harvested at 21 days post-cerulein injection (Fig. 3a). Pancreata from $\operatorname{Kras}^{G 12 D}$-Prdm3 ${ }^{\Delta A c i n a r}$ mice had full spectrum of precursor lesions including low-grade 
a

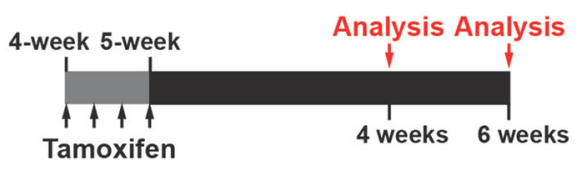

C

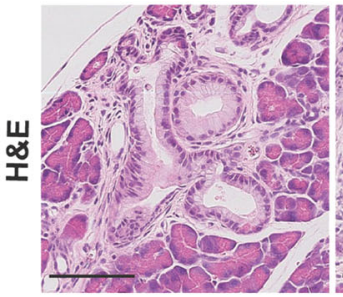

Mouse \#736

d
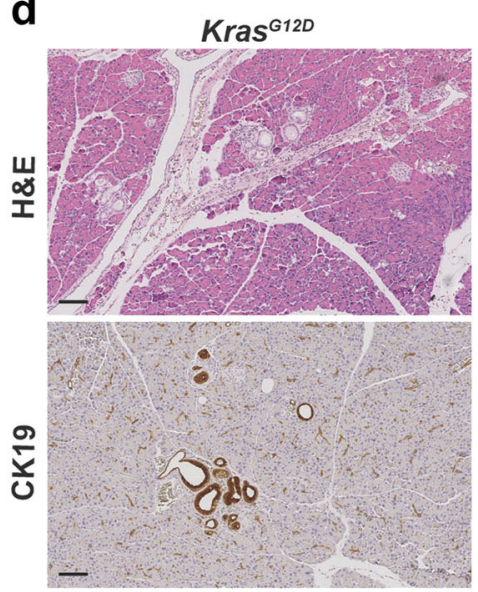

Mouse \#740

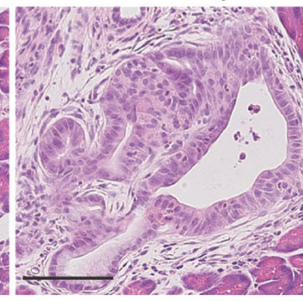

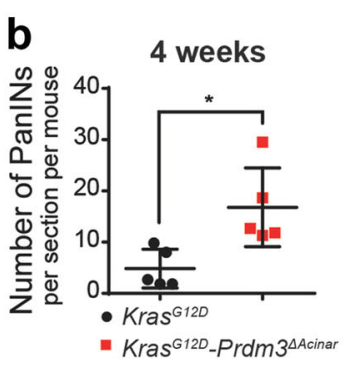

4 weeks (Kras ${ }^{G 12 D_{-}}$Prdm $\left.^{\Delta A c i n a r}\right)$

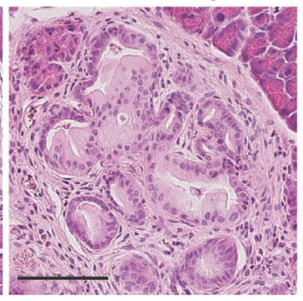

Mouse \#757

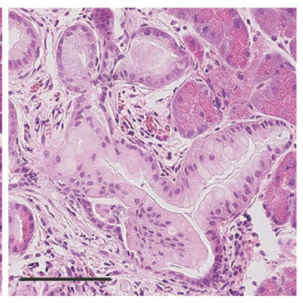

Mouse \#760
Kras $^{\mathrm{G12D}}$-Prdm $3^{\mathrm{AAcinar}}$
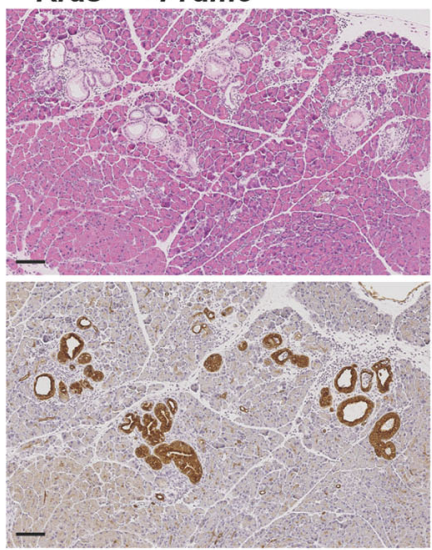

6 weeks
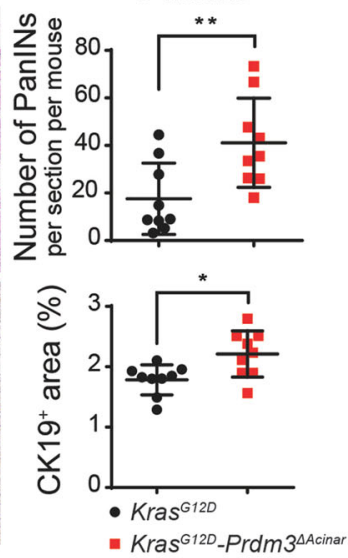
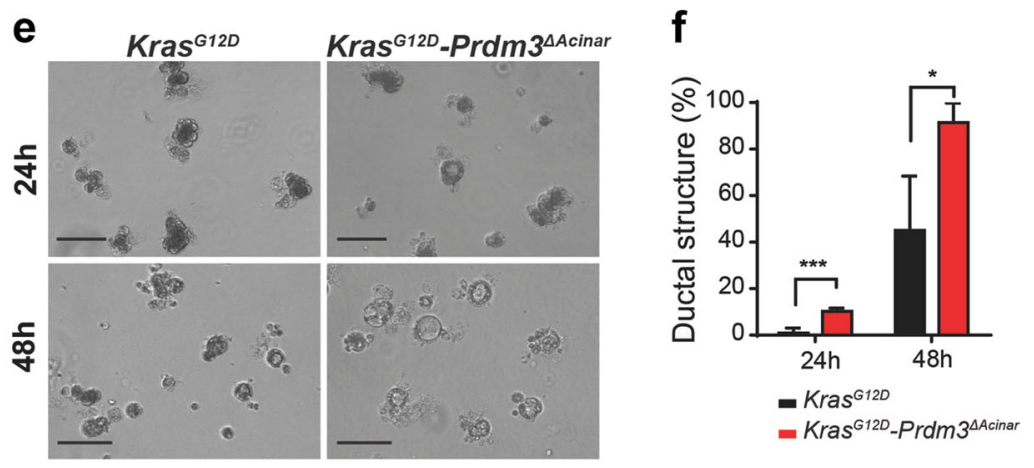

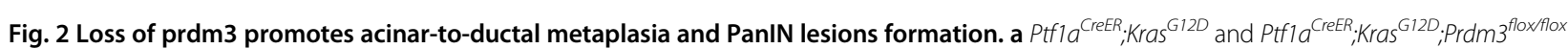
mice at 4-5 weeks of age were injected 4 times on alternating days with tamoxifen. Recombined mice were analyzed at 4 and 6 weeks post tamoxifen injection. $\mathbf{b}$ The number of PanINs per section for $\operatorname{Kras}^{G 12 D}(n=5)$ vs. Kras ${ }^{G 12 D}$-Prdm3 $3^{\Delta A c i n a r}(n=5)$ mice at 4 weeks post tamoxifen injection.

c Representative images of high-grade PanINs in Kras ${ }^{G 12 D}$-Prdm $3^{\triangle A c i n a r}$ mice at 4 weeks after tamoxifen injection. $\mathbf{d}$ Hematoxylin-eosin staining (H\&E) and immunohistochemistry staining for the ductal marker Cytokeratin 19 (CK19). Quantification of the number of PanINs, as well as the percent of pancreatic area that is $\mathrm{CK}_{1} 9^{+}$in $\mathrm{Kras}^{G 12 D}(n=9)$ vs. $\operatorname{Kras}^{G 12 D}{ }_{-} \operatorname{Prdm}^{\Delta A c i n a r}(n=9)$ mice 6 weeks post-tamoxifen injection. e Images of acinar cell explants embedded in Matrigel at 24 and $48 \mathrm{~h}$. $\mathbf{f}$ Quantification of the percent of ductal-like structures in explants derived from Kras ${ }^{G 12 D}(n=3)$ and Kras ${ }^{G 12 D}-P_{r d m} 3^{\Delta A c i n a r}$ $(n=3)$ mice at 4 weeks post-tamoxifen injection. Data show mean \pm SD. Statistical analysis: Two-tailed $t$-test. ${ }^{*} p<0.05,{ }^{* *} p<0.01,{ }^{* * *} p<0.001$.

Scale: $100 \mu \mathrm{m}$. 

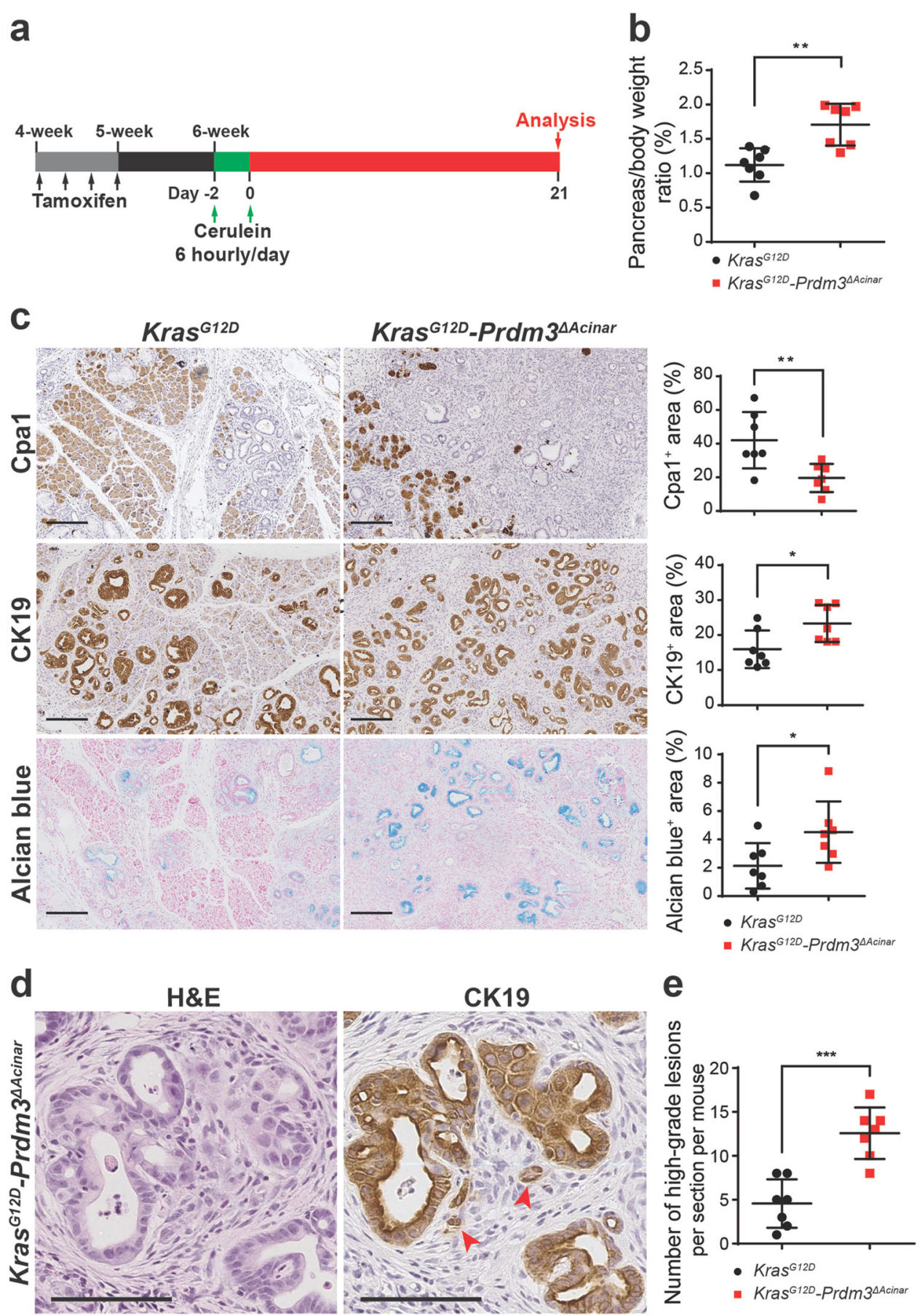

Fig. 3 Inhibition of Prdm3 accelerates Kras ${ }^{G 12 D}$-driven neoplastic transformation in response to pancreatitis. a Schematic illustration showing experimental design of cerulein-induced acute pancreatitis in cooperation with activation of oncogenic Kras in Ptfla-expressing cells. Ptfla ${ }^{\text {CreER }} ; \operatorname{Kras}^{G 12 D}(n=7)$ and Ptfla ${ }^{\text {CreER }} ; K_{\text {ras }}^{G 12 D} ; \operatorname{Prdm}^{\text {floxflox }}(n=7)$ mice at 4 to 5 weeks of age were injected 4 times on alternating days with tamoxifen. One week after the last tamoxifen injection, mice were subjected to cerulein $(50 \mu \mathrm{g} / \mathrm{kg})$ injection at hourly intervals over $6 \mathrm{~h}$ on alternating days separated by $24 \mathrm{~h}$ and analyzed at 21 days post cerulein injection. b Quantification of relative pancreas mass measured as percent of pancreas weight over body weight in $\mathrm{Kras}^{G 12 D}$ vs. Kras ${ }^{G 12 D}$-Prdm3 $3^{\triangle A c i n a r}$ mice. c Hematoxylin-eosin staining (H\&E) and immunohistochemistry for Cpa1, Cytokeratin 19 (CK19) and Alcian blue of pancreata from Kras ${ }^{G 12 D}$ and Kras ${ }^{G 12 D}$-Prdm3 $3^{\Delta A c i n a r}$ mice. Quantification of the percent of pancreatic area that is $\mathrm{Cpa}_{1}^{+}, \mathrm{CK}_{19}{ }^{+}$or Alcian blue ${ }^{+}$in $\mathrm{Kras}^{G 12 D}$ vs. Kras ${ }^{G 12 D}$-Prdm $3^{\Delta A c i n a r}$ mice. d Representative images of tumor budding in $\mathrm{Kras}^{G 12 D}$-Prdm $3^{\Delta A c i n a r}$ mice indicated by red arrowheads. Immunohistochemistry staining of CK19 strongly suggests invasive high-grade neoplasia. e Number of high-grade PanINs per section for each genotype. Data show mean \pm SD. Statistical analysis: Two-tailed $t$-test. ${ }^{*} p<0.05,{ }^{* *} p<0.01,{ }^{* * *} p<0.001$. Scale: $200 \mu m(\mathbf{c})$ and $100 \mu \mathrm{m}(\mathbf{d})$. 
PanINs, high-grade PanINs and ductal carcinoma in situ (Supplementary Fig. 3a), which had lost Prdm3 staining (Supplementary Fig. 3b). The control Kras ${ }^{G 12 D}$ mice had less evidence of tumorigenesis compared with $\mathrm{Kras}^{G 12 D_{-}}$ $\operatorname{Prdm} 3^{\Delta A c i n a r}$ mice. Specifically, in Kras ${ }^{G 12 D}-\operatorname{Prdm} 3^{\Delta A c i n a r}$ mice, the ratio of pancreas-to-body weight increased (Fig. 3b); the number of $\mathrm{Cpa1}^{+}$acinar cells decreased and CK $19^{+}$duct-like cells increased dramatically (Fig. 3c); a higher percentage of the pancreas was replaced by acidic mucin content indicated by Alcian blue staining (Fig. 3c); and the number of high-grade PanIN significantly elevated (Fig. 3e). Moreover, we consistently observed tumor budding associated with many high-grade neoplastic lesions in $\mathrm{Kras}^{G 12 D}$-Prdm3 ${ }^{\Delta A c i n a r}$ mice at 21 days postcerulein injection (Fig. 3d). Tumor budding is a strong prognostic indicator of aggressive tumor behavior, which is defined as the presence of single cells or clusters of less than five tumor cells scattered in the stroma ${ }^{21}$. In contrast to $\mathrm{Kras}{ }^{G 12 D}$-Prdm $3^{\Delta A c i n a r}$ mice, tumor budding was rarely observed in Kras ${ }^{G 12 D}$ mice, suggesting that loss of Prdm3 accelerates pancreatic cancer formation in $\mathrm{Kras}^{\mathrm{G} 12 D_{-}}$ expressing mice. Together, our data suggest that progression of low-grade precursor lesions to high-grade PanIN is more rapid in the absence of Prdm3.

\section{Loss of Prdm3 in acinar cells enhances pancreatitis}

Given that inflammation promotes cancer formation and $\operatorname{Prdm} 3$ was significantly increased in humans with pancreatitis, we further determined whether Prdm3 modulated the inflammatory response of the pancreas in Ptfla ${ }^{\text {CreER }}$;Prdm $3^{\text {flox fllox }}$ mice. Mice injected with tamoxifen, but lacking the Prdm $3^{\text {flox }}$ allele, were used as controls (Ptf1a ${ }^{C r e E R}$ mice). Seven days after tamoxifen administration Prdm3 protein was absent in more than $80 \%$ of acinar cells in Prdm3 $3^{\Delta A c i n a r}$ mice, indicating efficient and specific deletion of Prdm3 (Supplementary Fig. 4a). Acute pancreatitis was induced with intraperitoneal injection of cerulein, as described previously ${ }^{22}$ (Fig. 4a). Specifically, 7 days after the last tamoxifen injection, $\operatorname{Prdm} 3^{\Delta A c i n a r}$ and control $\left(P t f 1 a^{C r e E R}\right)$ mice were injected with $50 \mu \mathrm{g} / \mathrm{kg}$ cerulein at hourly intervals for $8 \mathrm{~h}$. Histological assessment of pancreata from mice $3 \mathrm{~h}$ after the last cerulein injection demonstrated exaggerated interstitial edema, cytoplasmic vacuolization and immune cell infiltration in $\operatorname{Prdm} 3^{\Delta A c i n a r}$ mice compared with control mice (Fig. 4b). Consistently, examination of immune cell infiltration demonstrated a substantial increase in the number of F4/ $80^{+}$macrophages, as well as Ly6B. $2^{+}$neutrophils in cerulein-treated $\operatorname{Prdm} 3^{\Delta \text { Acinar }}$ pancreata (Fig. 4b). Elevated blood amylase levels are an indicator of pancreatitis. Consistent with the increased inflammatory infiltrates in the pancreas, we observed significantly higher levels of serum amylase in Prdm3 ${ }^{\Delta A c i n a r}$ mice compared to controls (Fig. 4c). To determine whether the expression of inflammatory cytokines is increased, we harvested RNA from pancreata of $P r d m 3^{\Delta A c i n a r}$ and control mice to perform quantitative qRT-PCR. As expected, expression of inflammatory cytokines, including $\mathrm{Il}-6, \mathrm{Cxcl}-1, \mathrm{Cxcl}-10$, $\mathrm{Ccl} 2$, and $\mathrm{Ccl} 20$, increased significantly in $\mathrm{Prdm} 3$-deleted pancreata compared to control pancreata (Supplementary Fig. 4b). We further examined pancreata harvested from $\operatorname{Prdm} 3^{\Delta A c i n a r}$ and control mice $48 \mathrm{~h}$ after two series of 8hourly injection of cerulein (Fig. 4a). Characterization by immunohistochemistry for the ductal marker CK19 confirmed that acini undergoing acinar-to-ductal metaplasia increased dramatically in $\operatorname{Prdm} 3^{\Delta \text { Acinar }}$ mice (Fig. 4d). These results illustrate that acinar-cell-specific ablation of $\operatorname{Prdm} 3$ augments the severity of pancreatitis, suggesting a specific role of Prdm3 as a modulator of inflammatory response in the pancreas.

\section{Loss of Prdm3 activates inflammatory response and Hif-1 signaling pathways}

Injured acinar cells initiate inflammatory responses by releasing digestive enzymes and proinflammatory mediators such as a variety of cytokines. These cytokines in turn attract and activate macrophages to produce excessive inflammatory cytokines, like tumor necrosis factor-alpha (TNF- $\alpha$ ) and interleukin-1 beta (IL-1 $\beta$ ), to exacerbate tissue injury ${ }^{23,24}$. To investigate whether loss of Prdm3 alters cytokines secretion by pancreatic acinar cells, we performed a cytokine array assay on primary acinar cells in response to stimuli. Briefly, acinar cell clusters were isolated from a cohort of Prdm $3^{\Delta A c i n a r}$ and control $\left(P t f 1 a^{C r e E R}\right)$ mice, respectively, and subsequently cultured in the presence of cerulein or TNF- $\alpha$ for $6 \mathrm{~h}$. We found that among 40 cytokines detected in a mouse inflammatory array, macrophage inflammatory protein (MIP)- $1 \alpha$ and regulated upon activation normal $\mathrm{T}$ expressed and secreted (RANTES) were remarkably increased in $\operatorname{Prdm} 3^{\Delta A c i n a r}$ incubation medium (Fig. 5a). As MIP-1 $\alpha$ and RANTES are potent chemotactic agents for monocytes, we further examined macrophage activation in response to conditioned media from ceruleinstimulated cell cultures. The murine macrophages, Raw246.7 cells, were incubated in conditioned media collected from $\operatorname{Prdm} 3^{\Delta \text { Acinar }}$ or control cell culture exposed to cerulein for $6 \mathrm{~h}$ (Fig. 5b). After 16-hour incubation, the activation of macrophages was determined by the expression of inflammatory cytokines. We found that the relative expression of inflammatory cytokines Tnf- $\alpha$ and $I l-1 \beta$ was significantly higher in Raw246.7 incubated with $\operatorname{Prdm} 3^{\Delta A \text { Acinar }}$ conditioned media (Fig. 5b), supporting that more proinflammatory factors were released from Prdm3deficient cells to stimulate macrophage infiltration (Fig. 4b) and subsequent activation. These results indicate that Prdm $3^{\Delta \text { Acinar }}$ mice are more susceptible to ceruleininduced injury, at least, in part by contributing to increased macrophage activation. 


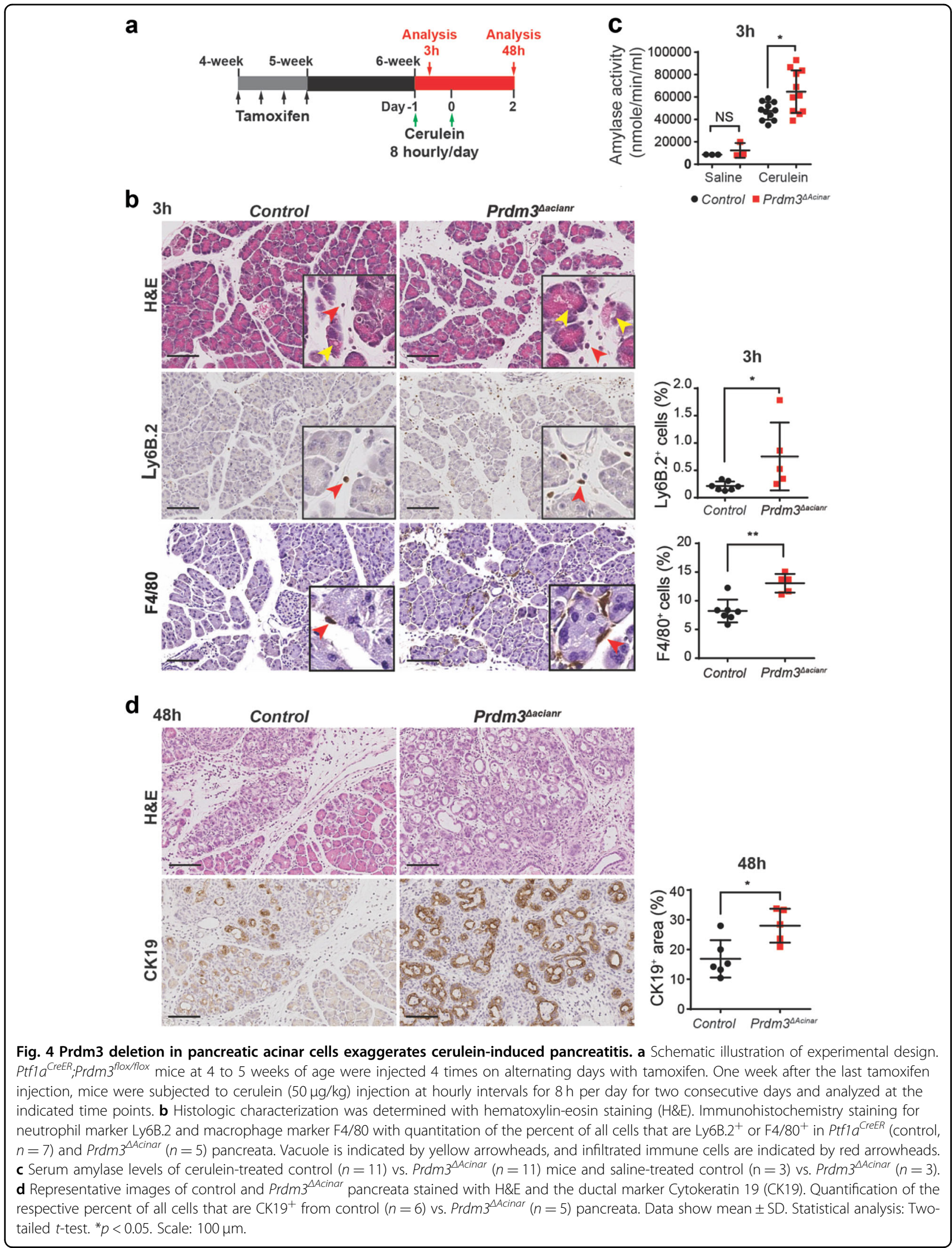


a

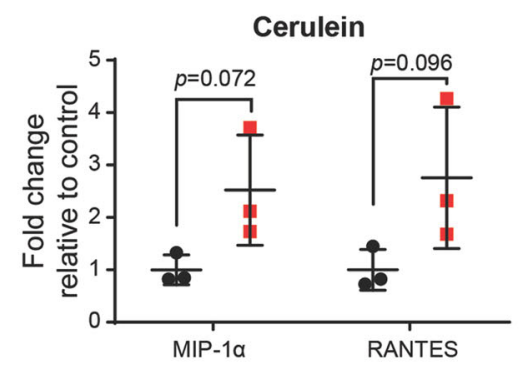

TNF- $\alpha$

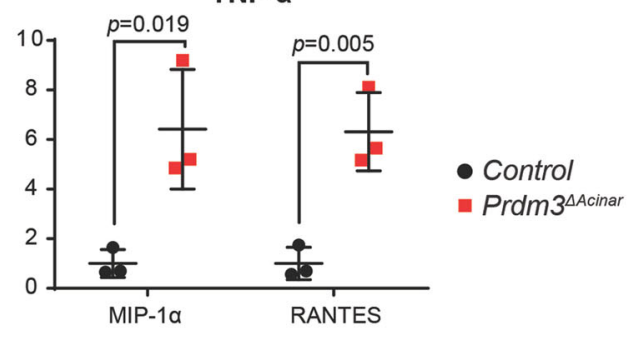

b
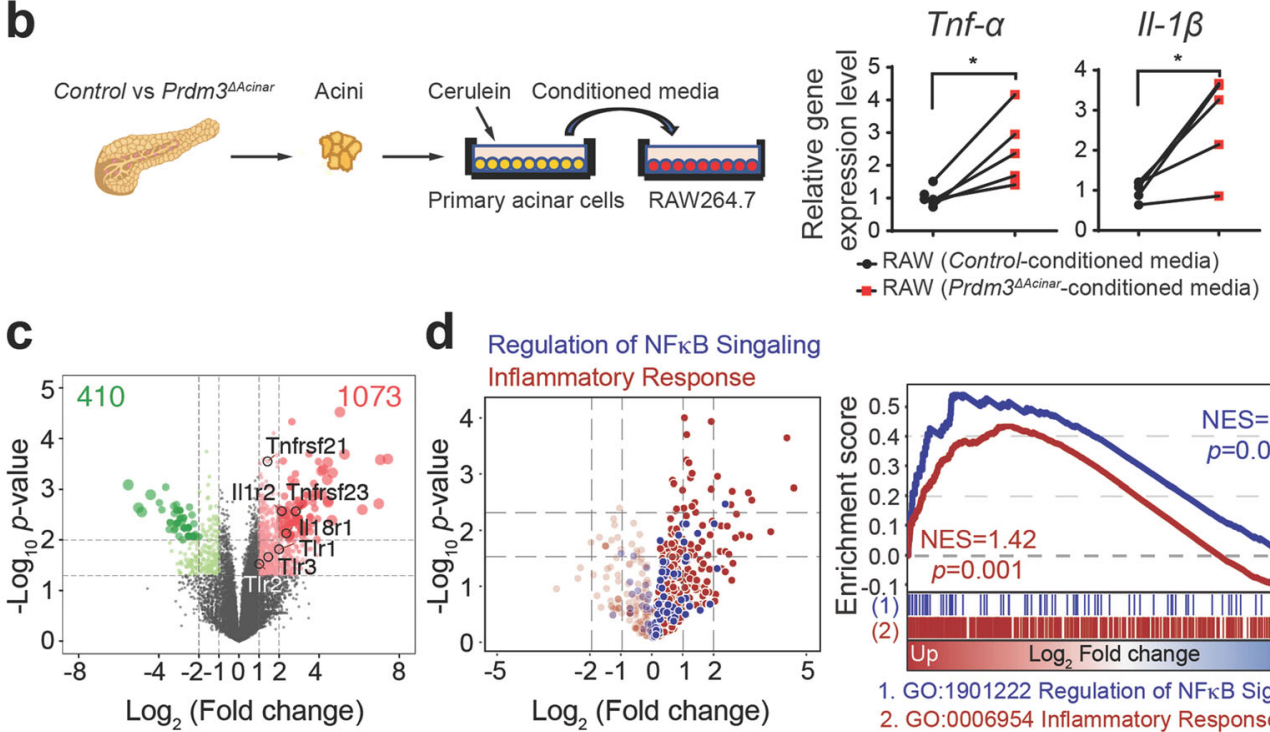

d Regulation of NFKB Singaling Inflammatory Response
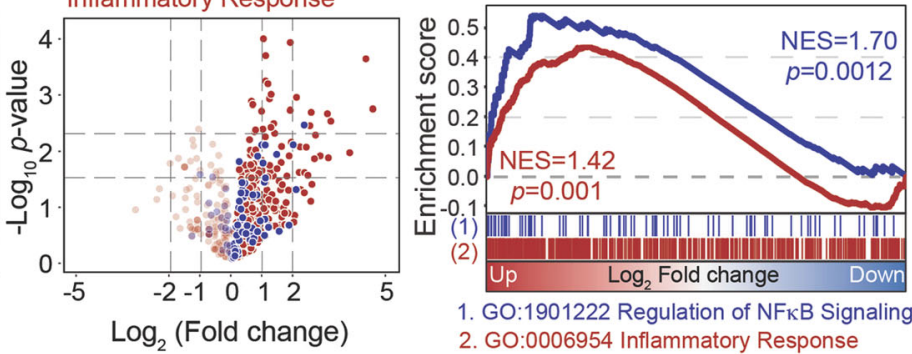

e Functional enrichment of upregulated

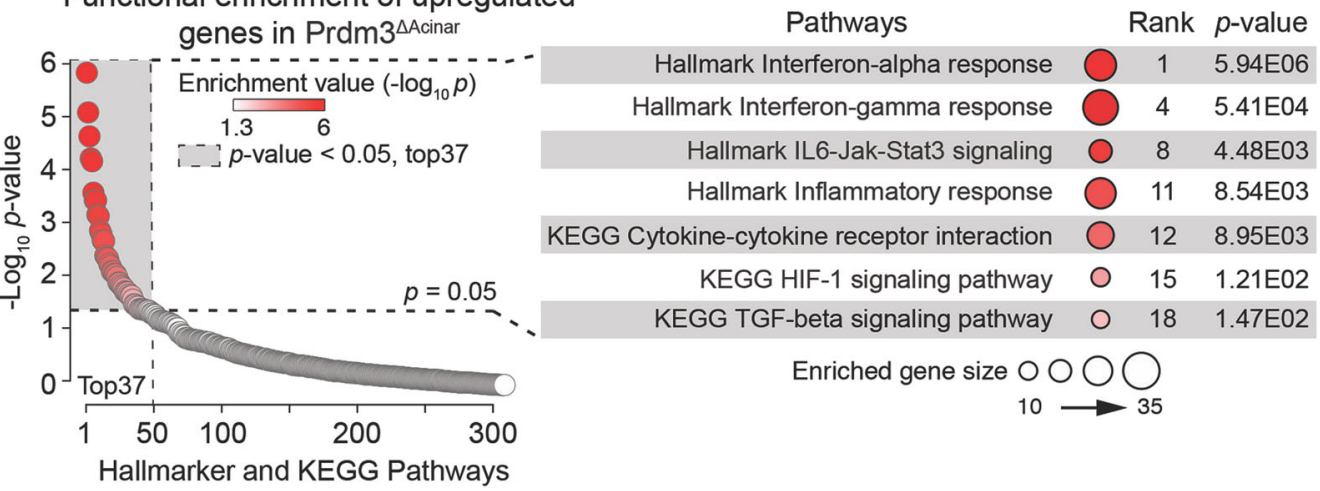

Fig. 5 Inactivation of Prdm3 enhances inflammatory response pathways. a Cytokine secretion was determined using a Raybiotech mouse inflammation array. Primary acinar cells, isolated from control $(n=3)$ and Prdm $3^{\triangle A c i n a r}(n=3)$ mice, were exposed to cerulein $(10 \mathrm{nM})$ or TNF-a $(100 \mathrm{ng} / \mathrm{ml})$ for $6 \mathrm{~h}$. Levels of cytokines (MIP-1a and RANTES) in culture medium were expressed relative to control. $p$-values were calculated based on two-tailed $t$-test. b Primary acinar cells were isolated from Prf1 $a^{\text {CreER }}(n=5) \mathrm{vs.} \operatorname{Prdm} 3^{\triangle A \text { Acinar }}(n=5)$ mice and cultured in Waymouth complete media in the presence of $10 \mathrm{nM}$ cerulein for $6 \mathrm{~h}$. Raw264.7 cells were treated with the above acinar-cell-conditioned media for $16 \mathrm{~h}$ and collected for quantitative real-time PCR for the indicated cytokines. Each set of connected dots in $\mathbf{b}$ depicts an independent biological replicate $(n=5$ experiments). Data show mean \pm SD. Statistical analysis: Two-tailed $t$-test. ${ }^{*} p<0.05$. $\mathbf{c}$ Volcano plot showing a total of 1483 differentially expressed genes in primary acinar cells isolated from Prdm $3^{\triangle A \text { cinar }}$ mice, relative to control Ptfia ${ }^{C r e E R}$. Individual genes are labeled and circled in black. $\mathbf{d}$ Volcano plot showing differentially expressed genes belonging to inflammatory responses and NF-KB signaling are highlighted in red and blue, respectively. Gene Set Enrichment Analysis (GSEA) of differentially expressed genes (Ptfla $a^{\text {CreER }}$ vs. Prdm3 ${ }^{\triangle A \text { Acinar }}$ ) identified enrichment of immune responses and regulation of NF-KB signaling. Normalized enrichment score (NES) and $p$-values are shown. e Functional annotation on 1073 upregulated genes in primary acinar cells isolated from Prdm $3^{\triangle A c i n a r}$ mice, relative to control. Significant KEGG and Hallmark terms, $p$-values and ranks are shown. 
To further examine the effect of Prdm3 deletion on acinar cell homeostasis, we performed transcriptome analyses of primary acinar cells isolated from $\operatorname{Prdm} 3^{\Delta \text { Acinar }}$ and control mice. Ptfla ${ }^{C r e E R}$; Prdm $3^{\text {flox/flox }}$ and control Ptfla ${ }^{C r e E R}$ mice were injected with four doses of tamoxifen at 4 to 5 weeks of age to induce recombination prior to acini isolation. One week after the last tamoxifen injection, primary acinar cells were isolated as described previously ${ }^{25}$ and then allowed to recover in oxygenated medium for $2 \mathrm{~h}$. Total RNA was extracted from these isolated acini and subjected to RNAseq analysis. The extent of Prdm3 deletion was confirmed in Prdm $3^{\Delta \text { Acinar }}$ pancreata (Supplementary Fig. 5a). Analysis of RNA-seq data sets was performed by DESeq2. Setting a $p$ value threshold of 0.05 , we identified 1483 genes that were significantly differentially expressed $\left(\log _{2} \mid\right.$ Fold change $\left.\mid>1\right)$ in Prdm3-deficient acini compared with control (Supplementary Table 2). Moreover, 1073 out of 1483 differentially expressed genes (DEGs) were upregulated, while only 410 of them were downregulated (Fig. 5c). We found that the expression of many adhesion molecules involved in the inflammatory response, such as the TNF receptor superfamily Tnfrsf 21 and Tnfrsf 23 , interleukin receptors Il18r1 and Il1r2, and toll like receptors Tlr1, Tlr2 and Tlr3 were significantly altered in Prdm3-deficient cells. Gene Set Enrichment Analysis (GSEA) further demonstrated that genes involved in inflammatory response and regulation of NF- $\mathrm{BB}$ signaling were significantly enriched in Prdm3deficient acinar cells (Fig. 5d). These findings support that loss of Prdm3 changes cellular homeostasis and biases acinar cells toward a proinflammatory state possibly by decreasing the inflammatory response threshold in Prdm $3^{\Delta \text { Acinar }}$ cells.

To further identify additional biological pathways that were activated upon Prdm3 deletion, we performed functional annotation on the 1703 upregulated genes with KEGG and Hallmark data sets. Loss of Prdm3 significantly affected over 30 pathways (Supplementary Table 3) including the Hif-1 signaling pathways (Fig. 5e). Intriguingly, recent studies demonstrated that mice with acinar cell-specific deletion of Hifl $\alpha$ were less susceptible to cerulein-induced pancreatitis ${ }^{26}$. As our transcriptome analysis revealed a significant elevation of Hifla in Prdm3-deficient cells, we compared the protein level of Hifla in control and Prdm $3^{\Delta \text { Acinar }}$ pancreata. We confirmed that the expression level of Hifla was significantly upregulated in Prdm3-depleted pancreatic tissue by immunoblotting and immunohistochemical staining (Supplementary Fig. 5b, c). Our findings are supported by a previous study in which shRNA knockdown of Prdm3 upregulated Hifla in DA-1 and NFS-60 leukemic cells ${ }^{27}$. As loss of Prdm3 exaggerated inflammation, we speculate that dysregulation of Hifla expression might contribute to the dramatic effects of Prdm3 depletion on pancreatitis.

\section{Discussion}

In the present study, we investigated the role of Prdm3 in pancreatitis and pancreatic tumorigenesis using mouse models to indelibly delete Prdm3 in adult acinar cells. We demonstrated that PRDM3 was substantially upregulated in pancreatic acinar cells of patients with pancreatitis, as well as well-differentiated PDAC, but not poorly differentiated PDAC. Interestingly, our clinical relevance analysis suggests a prognostic relevance of low PRDM3 expression in PDAC patients with surgical resection. Consistent herewith, we further demonstrated that loss of $\operatorname{Prdm} 3$ not only increased the severity of cerulein-induced pancreatitis, but also accelerated cellular atypia and tumorigenic potential in the pancreas, as Prdm3-deficient mice undergo robust formation of precursor lesions in the presence of oncogenic Kras. These findings implicate a potentially protective mechanism of $\mathrm{Prdm} 3$ in pancreatic exocrine cells, which is different from the pro-tumor role of PRDM3 in several aggressive forms of cancer including colon, breast and ovarian cancer ${ }^{28-30}$. A number of alternatively spliced variants, including the long and short forms of PRDM3, are expressed in pancreatic cancer cells ${ }^{14}$. Our studies cannot distinguish which forms of PRDM3 are necessary for its anti-tumor effect in acinar cells, therefore, more work will be needed to examine the effects of different PRDM3 isoforms on pancreatitis and pancreatic cancer initiation.

Previous studies demonstrated that Prdm3 promotes proliferation and migration in established pancreatic cancer cell lines ${ }^{14}$. However, when Prdm3 was knocked out in pancreatic acinar cells, we observed that Prdm3 depletion potentiated pancreatic cancer initiation and progression to high-grade lesions including ductal carcinoma in situ, suggesting that Prdm3 plays a suppressive role in acinar-to-ductal transformation. At a molecular level, we found that over $70 \%$ of the differentially expressed genes between normal and Prdm3-deficient acinar cells were upregulated in $\operatorname{Prdm} 3^{\Delta \text { Acinar }}$ mice, which is consistent with previous studies demonstrating that Prdm3 acts as a transcriptional repressor through interaction with a variety of co-repressors, such as CtBP, histone methyltransferase SUV39H1 and deacetylase HDAC $1 / 2^{10}$. We therefore postulate that increased Prdm3 expression in transformed ductal-like cells plays an inhibitory role in pancreatic tumorigenesis through the ability of Prdm3 to suppress a series of signaling cascades important for malignant transformation in exocrine pancreas.

Here, we showed that Prdm3-deficient acinar cells were much more susceptible to cerulein-induced injury. Loss of Prdm3 enhanced ADM formation, as well as macrophage and neutrophil infiltration. Our transcriptome analysis suggests that deletion of Prdm3 in adult pancreatic acini induces significant alteration in the expression profiles of 
cytokine/chemokine receptors, possibly accounting for greater responses to inflammatory stimuli. We speculate that accumulation of Prdm3 is beneficial to limit local inflammation by increasing the threshold for acinar cells to respond to cellular stress. Expression of oncogenic Kras in acinar cells triggers microinflammation and chemoattraction of macrophages ${ }^{31}$. Infiltrated macrophages secrete matrix-metalloproteinases and inflammatory cytokines, such as TNF- $\alpha$, to facilitate acinar-to-ductal transdifferentiation through a NF- $\mathrm{kB}$-mediated signaling cascase $^{32}$. Moreover, several lines of evidence suggest that inflammation leads to an increase of Ras activity and amplification of oncogenic Ras signaling, which is necessary for pancreatic cancer progression ${ }^{18,33,34}$. Activation of Kras alone in mice leads to PDAC formation at a low frequency and takes over one year ${ }^{35}$. In contrast, when pancreatitis was induced in $\mathrm{Kras}^{\mathrm{G12D}}$ mice, tumorigenesis occurred within a few months ${ }^{8,36}$ suggesting that precancerous lesions can arise from acinar cells through a process dramatically hastened by inflammation ${ }^{32}$. In this study, we demonstrated that loss of Prdm3 accelerated Kras ${ }^{G 12 D}$-induced PanIN initiation and promoted rapid progression of pre-neoplastic lesions to invasive lesions. Given that activation of inflammatory response elevates constitutive Ras activity, we propose that, loss of Prdm3 upregulates the expression of genes involved in inflammatory response in pancreatic acinar cells, which modulates acinar cell homeostasis to lower the threshold of acinar cells to inflammatory stimuli and promote widespread formation of precancerous lesions from Kras mutated acinar cells.

In addition, we found that hypoxia inducible factor Hifla was significantly upregulated in Prdm3-deficent acinar cells at both mRNA and protein levels. Our findings are consistent with the previous study in which knockdown of Prdm3 upregulated Hif1a in DA-1 and NFS-60 leukemic cells $^{27}$. It has also recently been established that HIF-1 signaling plays important roles in both pancreatitis and pancreatic cancer. Hifla is overexpressed in chronic pancreatitis $^{37}$ and its high expression is associated with poor prognosis in $\mathrm{PDAC}^{38,39}$. Acinar-cell-specific deletion of Hifla prevented intrapancreatic coagulation of fibrinogen and protected mice from cerulein-induced acute pancreatitis $^{26}$, suggesting a functional role of Hifla in the development of pancreatitis. Given that loss of Prdm3 exaggerated inflammation, we speculate that dysregulation of Hifla expression might contribute to the dramatic effects of Prdm3 depletion on pancreatitis.

Taken together, our data demonstrated that loss of Prdm3 not only increased the severity of cerulein-induced pancreatitis, but also accelerated cellular atypia and tumorigenic potential in the pancreas, as Prdm3-deficient mice undergo robust formation of precursor lesions in the presence of oncogenic Kras. We uncovered a previously unappreciated role for Prdm3 as a suppressor of both pancreatitis and pancreatic tumorigenesis presumably through regulating inflammatory and Hif-1 signaling pathways in the pancreatic acinar cells.

\section{Materials and methods \\ Human samples}

A total of 94 patients diagnosed with PDAC and 22 patients diagnosed with chronic pancreatitis between 2003-2011 were included in this study in accordance with institutional guidelines and approved by the Clinical Research Ethics Committee of the First Affiliated Hospital at Sun Yat-sen University. Written informed consent was received from participants prior to inclusion in this study.

\section{Mice}

All animal experiments were approved by the University of Macau Animal Ethics Committees and carried out in accordance to recommendations stated in the Guide for the Care and Use of Laboratory Animals for the National Institutes of Health (US Department of Health, Education, and Welfare). Prdm $3^{\text {flox/flox }}, K_{r a s}{ }^{L S L-G 12 D}$, and Ptfla ${ }^{\text {CreER }}$ mice have previously been described. Recombination was induced by four subcutaneous injection of tamoxifen every other day at $125 \mathrm{mg} / \mathrm{kg}$ body weight on animals at 4 to 5 weeks of age.

\section{Cerulein-induced pancreatitis}

To induce acute pancreatitis, experimental mice were fasted overnight before administration of cerulein as described previously ${ }^{4}$. Cerulein (American Peptide) was dissolved in saline and administrated intraperitoneally at $50 \mu \mathrm{g} / \mathrm{kg}$ body weight hourly for $8 \mathrm{~h}$. Mice were sacrificed after $3 \mathrm{~h}$ recovery. Alternatively, mice were injected with cerulein $(50 \mu \mathrm{g} / \mathrm{kg}$ body weight) at hourly intervals for $8 \mathrm{~h}$ per day for two consecutive days and sacrificed at $48 \mathrm{~h}$ after the last injection. To accelerate tumorigenesis, mice were given hourly injections of cerulein $(50 \mu \mathrm{g} / \mathrm{kg}$ body weight) for $6 \mathrm{~h}$ per day on alternating days separated by $24 \mathrm{~h}$ and sacrificed after 21 days.

\section{Histology and immunohistochemical analyses}

Paraffin-embedded sections were prepared and subjected to hematoxylin, eosin Y, Alcian blue or immunohistochemical staining. H\&E staining and IHC followed our established procedures ${ }^{5}$, including antigen retrieval with citrate buffer ( $\mathrm{pH}$ 6.0) prior to staining paraffin sections. For Alcian blue staining, paraffin sections were incubated in 3\% acetic acid for $3 \mathrm{~min}$, followed by staining in $1 \%$ Alcian blue staining solution for $30 \mathrm{~min}$, and subsequently in Nuclear Fast Red for $5 \mathrm{~min}$. All slides were scanned with a $20 \times$ objective using a $2 \mathrm{D}$ glass slide digital scanner (Leica Biosystems) and examined at high magnification using the Aperio ImageScope software (Leica 
Biosystems). The Aperio positive pixel Algorithm was used to quantify area with positive staining and Aperio nuclear V9 algorithm was used to quantify the number of nuclei. The percentages of Cpa1-positive, CK19-positive, Muc5AC-positive, and Alcian blue-positive area were calculated by positive pixels divided by the total pixels in selected tissue areas. The percentages of Ly6B.2-positive, and Prdm3-positive cells were calculated by positive number of nuclei divided by the total number of nuclei in selected tissue areas. Six sections, which displayed maximal pancreatic cross-sectional area, from each animal were used for quantification. The number of PanINs were counted based on the characteristics of every gland with cuboidal to columnar duct-like structures and enlarged lumen in six sections per mouse. For the number of highgrade lesions, including PanINs and ductal carcinoma in situ, five $1600 \times 920 \mu \mathrm{m}$ squares in one section per mouse were analyzed and the squares were randomly distributed in the pancreas. Primary and secondary antibodies used for staining is provided in Supplementary Table 4.

\section{Evaluation of immunostaining of PRDM3 in patient specimens}

PRDM3 expression was evaluated according to the staining intensity and proportion of positively stained tumor cells. Staining intensity was graded as 0 (negative), 1 (weakly positive), 2 (moderately positive), and 3 (strong positively). The proportion of positively stained tumor cells was scored as 0 (no positive cells), 1 ( $<10 \%$ positive cells), 2 (10-25\% positive cells), 3 (25-50\% positive cells), and 4 ( $>50 \%$ positive cells). The immunostaining of PRDM3 was determined by staining index (SI) through multiplying the staining intensity by the proportion of positively stained tumor cells as previously described ${ }^{40}$. The expression levels of PRDM3 was regarded as high if the SI score is $>6$, or low if the SI score if $\leq 6$. The immunohistochemical specimens were evaluated by two independently pathologists who were blinded to clinical diagnosis.

\section{RNA isolation and quantitative real-time PCR}

Mice were sacrificed with $\mathrm{CO}_{2}$ asphyxiation followed by cervical dislocation. Pancreata were immediately harvested and cut into small pieces in RNALater (Qiagen). To detect mRNAs, $20 \mathrm{mg}$ of tissue was homogenized in $1 \mathrm{ml}$ of Trizol using a T 10 basic ULTRA-TURRAX ${ }^{\circledR}$ homogenizer. RNA was extracted from Trizol according to the manufacturer's instructions (Thermo Fisher Scientific) and subsequently subjected to reverse transcription using the PrimeScript ${ }^{\mathrm{TM}}$ RT reagent Kit (TaKara). Quantitative real-time PCR was performed with the Premix Ex Taq (TaKara) on a CFX96 qPCR system (BioRad). Results were normalized to Gapdh for mRNA detection.
The quantitative real-time PCR primer sequences are list in Supplementary Table 5.

\section{Western blotting}

Pancreata were harvested and snap frozen in liquid nitrogen. The frozen tissue was homogenized in lysis buffer containing $20 \mathrm{mM}$ Tris- $\mathrm{HCl}(\mathrm{pH} 7.5), 150 \mathrm{mM}$ $\mathrm{NaCl}, 1 \mathrm{mM} \mathrm{Na}{ }_{2}$ EDTA, $2 \mathrm{mM} \mathrm{Na} \mathrm{VO}_{4}, 1 \%$ Triton X-100, $5 \mathrm{mM}$ 4-nitrophenyl phosphate, $0.5 \%$ sodium deoxylcholate, $1 \mathrm{mM}$ phenylmethanesulfonylfluoride, and protease inhibitor cocktail (Sigma). $20 \mu \mathrm{g}$ of protein was separated on a $10 \%$ sodium dodecyl sulfatepolyacrylamide gel, transferred onto a polyvinylidene difluoride membrane, and probed with antibodies. The membranes were visualized using the ECL ${ }^{\mathrm{Tm}}$ Western Blotting Detection System (GE Healthcare) and ChemiDoc $^{\mathrm{TM}}$ Imaging Systems (BioRad).

\section{Serum amylase assay}

Blood was collected by cardiac puncture and placed at room temperature for $30 \mathrm{~min}$. Serum was separated from red blood cells by centrifugation at $2500 \times g$ for $15 \mathrm{~min}$. The top layer which contained serum was transferred to a new tube for further analysis. Amylase activity was measured using the Amylase Colorimetric Assay Kit (Sigma) following manufacturer's instructions.

\section{Isolation of primary acinar cells}

Primary acinar cells were isolated as described in detail previously ${ }^{25}$ with a small modification. In brief, pancreas was harvested and transferred into ice-cold Hank's balanced salt solution (HBSS). Lymph nodes, fat and mesenteric tissues were carefully removed. Pancreas was minced into 2-mm to 3-mm pieces and digested with $0.2 \mathrm{mg} / \mathrm{ml}$ collagenase $\mathrm{P}$ (Roche) at $37^{\circ} \mathrm{C}$ for $10-12 \mathrm{~min}$. Cell clusters were washed 3 times with ice-cold HBSS containing 5\% FBS and filtered through 100- $\mu \mathrm{m}$ cell strainer (BD Biosciences). The cell suspension containing acini was carefully layered on top of HBSS containing $30 \%$ FBS. Primary acinar cells were pelleted $(80 \times \mathrm{g}, 2 \mathrm{~min}$, at $4{ }^{\circ} \mathrm{C}$ ) and resuspended in Waymouth media (Sigma).

\section{RAW246.7 cell culture and activation}

Raw264.7 macrophages were obtained from American Type Culture Collection (ATCC) and maintained in DMEM (Gibco) containing 10\% FBS and $100 \mathrm{U} / \mathrm{ml}$ penicillin/streptomycin in a $37^{\circ} \mathrm{C}$ humified incubator supplemented with $5 \% \mathrm{CO}_{2}$. To stimulate macrophage activation, $5 \times 10^{5}$ Raw264.7 cells per well of 24-well plate were culture in DMEM (10\% FBS and $100 \mathrm{U} / \mathrm{ml}$ penicillin/streptomycin) overnight and then incubated in acinar-cell-conditioned media. To obtain acinar-cellconditioned media, primary acinar cell clusters isolated from an equal mass of $\operatorname{Prdm} 3^{\Delta \text { Acinar }}$ or control pancreata 
were incubated in Waymouth complete media (10\% FBS, $10 \mathrm{mM}$ HEPES, $100 \mathrm{U} / \mathrm{ml}$ penicillin/streptomycin, $100 \mu \mathrm{g} /$ $\mathrm{ml}$ Soybean Trypsin Inhibitor, and $1 \mu \mathrm{g} / \mathrm{ml}$ Dexamethasone) containing $10 \mathrm{nM}$ cerulein for $6 \mathrm{~h} .0 .5 \mathrm{ml}$ cell-free supernatants were collected and applied to Raw264.7 cells for $16 \mathrm{~h}$. RNA from Raw264.7 macrophages was extracted for quantitative real-time PCR. Data were normalized to Gapdh, as well as the amount of proteins extracted from primary acinar cells used to prepare conditioned media.

\section{Mouse cytokine array}

Six-week-old recombinant $P t f 1 a^{C r e E R} ; P r d m 3^{f l o x} f$ flox and $P t f 1 a^{C r e E R}$ mice were sacrificed one week after the last tamoxifen injection. Primary acinar cells were isolated from an equal mass of $\operatorname{Prdm} 3^{\Delta A c i n a r}(n=3)$ and control $(n=3)$ pancreata as described above. To stimulate cytokine release, acinar cell explants were incubated in $0.5 \mathrm{ml}$ Waymouth complete medium in the presence of cerulein $(10 \mathrm{nM})$ or TNF $\alpha(100 \mathrm{ng} / \mathrm{ml})$ for $6 \mathrm{~h} .100 \mu \mathrm{l}$ of supernatants was collected to examine the concentration of 40 cytokines using the Quantibody ${ }^{\circledast}$ Mouse Inflammatory Array Kit (RayBiotech, Catalog number QAM-INF-1) according to the manufacturer's instructions. The fluorescent signal was detected using an $\operatorname{InnoScan}^{\circledR} 300$ Microarray Scanner and analyzed by the GenePix ${ }^{\circledR}$ Microarray Analysis Software.

\section{D acinar cell explant culture}

Three-dimensional Matrigel explant culture of acinar cells was performed as described previously ${ }^{41}$. In brief, freshly isolated primary acinar cell clusters were prepared as above, embedded in growth factor reduced Matrigel (BD Biosciences), cultured in Waymouth complete medium, and maintained at $37^{\circ} \mathrm{C}$ in $5 \% \mathrm{CO}_{2}$ atmosphere. To stimulate acinar to ductal transdifferentiation in the absence of mutant Kras, control and Prdm3 $3^{\Delta A c i n a r}$ acinar explants were treated with $50 \mathrm{ng} / \mathrm{ml}$ TGF- $\alpha$. The ratio of acinar to ductal conversion was determined with an average of ten random $10 \times$ fields using the EVOS FL Imaging System (Thermo Fisher Scientific).

\section{RNA-seq analyses}

Total RNA was extracted from primary acinar cells freshly isolated from 6-week-old Ptf1a ${ }^{\mathrm{CreER}} ; \mathrm{Prdm} 3^{\text {flox/flox }}$ mice $(n=2)$ and their corollary controls (Ptf1a ${ }^{\mathrm{CreER}}, n=$ $2)$, one week after the last tamoxifen injection $(125 \mathrm{mg} / \mathrm{kg}$, 4 times, every other day). RNA concentration and integrity were measured using the Agilent 2100 Bioanalyzer (Agilent Technologies). PolyA tailed RNA were selected using Dynabeads ${ }^{\circledR}$ oligo(dT) (Thermo Fisher Scientific). cDNA libraries were prepared using the NEBNext ${ }^{\oplus}$ Ultra $^{\mathrm{TM}}$ RNA Library Prep Kit for Illumina (New England Biolabs) according to the manufacturer's instructions.
Libraries were sequenced at Novogene (Tianjin, China) with $100 \times$ coverage and 150 bp paired end reads on an Illumina HiSeq 2500 instrument.

The quality of the sequencing data was analyzed by using FastQC (version 0.11.5), and raw reads with low quality were removed using Trim Galore (version 0.4.4) prior to analysis of the data. All the trimmed reads were mapped to reference mouse genome (mm10, GRCm38) by using STAR (version 020201), and the mapped counts were extracted using feature count from Subread package (version 1.5.3). Subsequently, read count data containing 49,492 quantified transcripts with raw reads was preprocessed by filtering out genes with zero read count across different samples, and 20,069 genes remained after filtering. The read count data were normalized by DESeq2, which can be used for downstream differential expression analysis. Differentially expressed genes (DEG) in $\operatorname{Prdm} 3^{\Delta \text { Acinar }}$ vs. control were filtered by $\mid \log _{2}$ fold change $\mid>1$. $P$-values were determined using moderated $t$ statistics implemented in the Limma package. Gene set enrichment analysis (GSEA) was performed using Bioconductor $\mathrm{R}$ package clusterProfiler ${ }^{42,43}$. The gene sets implemented were derived from Cancer hallmark, Kyoto Encyclopedia of Genes and Genomes (KEGG) and Gene Ontology (GO), which was collected in the Molecular Signatures Database (MSigDB; version 6.2). Functional enrichment was performed on genes upregulated Prdm3deficient cells. RNA-seq raw data generated for this manuscript is available in the NCBI Sequence Read Archive (SRA) accession number PRJNA605571.

\section{Statistical analysis}

All data are presented as mean \pm SD from at least three mice in each experimental group. Statistical analysis between two groups was acquired using two-tailed Student's $t$-test. Statistical analyses of patient samples were performed with SPSS software using two-sided $t$-test. Kaplan-Meier survival plots were generated using the logrank test. Statistical analysis for RNA-seq data is described in the corresponding sections. $P$-value $<0.05$ was considered statically significant.

\section{Acknowledgements}

We thank the University of Macau, Faculty of Health Sciences, Animal Research Facility for animal housing. We thank Christopher Wright (Vanderbilt University) for Ptf1 ${ }^{\text {CreER }}$ mice and David Tuveson (Cold Spring Harbor Laboratory) for LSLKras $^{G 12 D}$ mice. This work was supported by the National Natural Science Foundation of China (NSFC 31701276) and the Science and Technology Development Fund of Macau SAR (FDCT 170/2017/A3 and FDCT 0033/2019/ A1) to R.X., Canadian Institutes of Health Research Operating Grant (mop142216) and New Investigator Award to J.L.K., National Natural Science Foundation of China (NSFC 81672417) to W.L., and National Institutes of Health (R01-DK078803) to M.S.

\footnotetext{
Author details

${ }^{1}$ Cancer Centre, Faculty of Health Sciences, University of Macau, 999078 Macau SAR, China. ${ }^{2}$ Institute of Translational Medicine, Faculty of Health of Sciences,
} University of Macau, 999078 Macau SAR, China. 'aboratory of General Surgery, 
The First Affiliated Hospital, Sun Yat-sen University, 510275 Guangzhou, China. ${ }^{4}$ Division of Medical Sciences, National Cancer Centre Singapore, Duke-NUS Medical School, Singapore 169857, Singapore. ${ }^{5}$ Department of Cellular and Physiological Sciences, University of British Columbia, Vancouver, BC V6T 1Z4, Canada. ${ }^{6}$ Department of Hematology and Oncology, University of Tokyo, Tokyo 113-8654, Japan. ${ }^{7}$ Department of Pediatrics and Cellular and Molecular Medicine, University of California-San Diego, La Jolla, CA 92093, USA. ${ }^{8}$ Department of Pathology and Laboratory Medicine, University of British Columbia, Vancouver, BC V6T 1Z4, Canada

\section{Conflict of interest}

The authors declare that they have no conflict of interest.

\section{Publisher's note}

Springer Nature remains neutral with regard to jurisdictional claims in published maps and institutional affiliations.

Supplementary Information accompanies this paper at (https://doi.org/ 10.1038/s41419-020-2371-x).

Received: 10 October 2019 Revised: 19 February 2020 Accepted: 19 February 2020

Published online: 16 March 2020

\section{References}

1. Siegel, R. L., Miller, K. D. \& Jemal, A. Cancer statistics, 2019. CA Cancer J. Clin. 69 7-34 (2019).

2. Murtaugh, L. C. \& Keefe, M. D. Regeneration and repair of the exocrine pancreas. Annu. Rev. Physiol. 77, 229-249 (2015).

3. Storz, P. Acinar cell plasticity and development of pancreatic ductal adenocarcinoma. Nat. Rev. Gastroenterol. Hepatol. 14, 296-304 (2017).

4. Morris, J. P. t., Cano, D. A., Sekine, S., Wang, S. C. \& Hebrok, M. Beta-catenin blocks Kras-dependent reprogramming of acini into pancreatic cancer precursor lesions in mice. J. Clin. Invest. 120, 508-520 (2010).

5. Kopp, J. L. et al. Identification of Sox9-dependent acinar-to-ductal reprogramming as the principal mechanism for initiation of pancreatic ductal adenocarcinoma. Cancer Cell 22, 737-750 (2012).

6. Habbe, N. et al. Spontaneous induction of murine pancreatic intraepithelial neoplasia (mPanIN) by acinar cell targeting of oncogenic Kras in adult mice. Proc. Natl Acad. Sci. USA 105, 18913-18918 (2008).

7. McAllister, F. et al. Oncogenic Kras activates a hematopoietic-to-epithelial IL-17 signaling axis in preinvasive pancreatic neoplasia. Cancer Cell $\mathbf{2 5}, 621-637$ (2014).

8. Guerra, C. et al. Chronic pancreatitis is essential for induction of pancreatic ductal adenocarcinoma by K-Ras oncogenes in adult mice. Cancer Cell $\mathbf{1 1}$ 291-302 (2007).

9. Hassan, M. M. et al. Risk factors for pancreatic cancer: case-control study. Am. J. Gastroenterol. 102, 2696-2707 (2007).

10. Glass, C., Wilson, M., Gonzalez, R., Zhang, Y. \& Perkins, A. S. The role of EVl1 in myeloid malignancies. Blood Cells Mol. Dis. 53, 67-76 (2014).

11. Hohenauer, T. \& Moore, A. W. The Prdm family: expanding roles in stem cells and development. Development 139, 2267-2282 (2012).

12. Goyama, S. et al. Evi-1 is a critical regulator for hematopoietic stem cells and transformed leukemic cells. Cell Stem Cell 3, 207-220 (2008).

13. Zhang, Y. et al. PR-domain-containing Mds1-Evi1 is critical for long-term hematopoietic stem cell function. Blood 118, 3853-3861 (2011)

14. Tanaka, M. et al. EVI1 oncogene promotes KRAS pathway through suppression of microRNA-96 in pancreatic carcinogenesis. Oncogene 33, 2454-2463 (2014).

15. Diaferia, G. R. et al. Dissection of transcriptional and cis-regulatory control of differentiation in human pancreatic cancer. EMBO J. 35, 595-617 (2016).

16. Kopinke, D. et al. Ongoing Notch signaling maintains phenotypic fidelity in the adult exocrine pancreas. Dev. Biol. 362, 57-64 (2012).

17. Jackson, E. L. et al. Analysis of lung tumor initiation and progression using conditional expression of oncogenic K-ras. Genes Dev. 15 3243-3248 (2001).
18. Ardito, C. M. et al. EGF receptor is required for KRAS-induced pancreatic tumorigenesis. Cancer Cell 22, 304-317 (2012).

19. Means, A. L. et al. Pancreatic epithelial plasticity mediated by acinar cell transdifferentiation and generation of nestin-positive intermediates. Development 132, 3767-3776 (2005).

20. Sandgren, E. P., Luetteke, N. C., Palmiter, R. D., Brinster, R. L. \& Lee, D. C. Overexpression of TGF alpha in transgenic mice: induction of epithelial hyperplasia, pancreatic metaplasia, and carcinoma of the breast. Cell 61, 1121-1135 (1990)

21. Berg, K. B. \& Schaeffer, D. F. Tumor budding as a standardized parameter in gastrointestinal carcinomas: more than just the colon. Mod. Pathol. 31 862-872 (2018).

22. Jensen, J. N. et al. Recapitulation of elements of embryonic development in adult mouse pancreatic regeneration. Gastroenterology $\mathbf{1 2 8}$ 728-741 (2005).

23. Shrivastava, P. \& Bhatia, M. Essential role of monocytes and macrophages in the progression of acute pancreatitis. World J. Gastroenterol. 16, 3995-4002 (2010).

24. Lugea, A. et al. Human pancreatic acinar cells: proteomic characterization, physiologic responses, and organellar disorders in ex vivo pancreatitis. Am. J. Pathol. 187, 2726-2743 (2017).

25. Gruber, R. et al. YAP1 and TAZ control pancreatic cancer initiation in mice by direct up-regulation of JAK-STAT3 signaling. Gastroenterology 151, 526-539 (2016).

26. Park, M. J. et al. HIF1-alpha regulates acinar cell function and response to injury in mouse pancreas. Gastroenterology 154, 1630-1634 (2018).

27. Glass, C. et al. Global identification of EVI1 target genes in acute myeloid leukemia. PLoS ONE 8, e67134 (2013).

28. Wang, $\mathrm{H}$. et al. Prominent oncogenic roles of EVI1 in breast carcinoma. Cancer Res. 77, 2148-2160 (2017).

29. Nanjundan, M. et al. Amplification of MDS1/EVI1 and EVI1, located in the 3 q26.2 amplicon, is associated with favorable patient prognosis in ovarian cancer. Cancer Res. 67, 3074-3084 (2007).

30. Deng, $\mathbf{X}$. et al. Overexpression of Evi-1 oncoprotein represses TGF-beta signaling in colorectal cancer. Mol. Carcinog. 52, 255-264 (2013).

31. Liou, G. Y. et al. Mutant KRAS-induced expression of ICAM-1 in pancreatic acinar cells causes attraction of macrophages to expedite the formation of precancerous lesions. Cancer Disco. 5, 52-63 (2015).

32. Liou, G. Y. et al. Macrophage-secreted cytokines drive pancreatic acinar-toductal metaplasia through NF-kappaB and MMPs. J. Cell Biol. 202, 563-577 (2013).

33. Ji, B. et al. Ras activity levels control the development of pancreatic diseases. Gastroenterology 137, 1072-1082 (2009).

34. Guerra, C. et al. Pancreatitis-induced inflammation contributes to pancreatic cancer by inhibiting oncogene-induced senescence. Cancer Cell 19, 728-739 (2011).

35. Hingorani, S. R. et al. Preinvasive and invasive ductal pancreatic cancer and its early detection in the mouse. Cancer Cell 4, 437-450 (2003).

36. Carriere, C., Young, A. L., Gunn, J. R., Longnecker, D. S. \& Korc, M. Acute pancreatitis markedly accelerates pancreatic cancer progression in mice expressing oncogenic Kras. Biochem. Biophys. Res. Commun. 382, 561-565 (2009).

37. Crnogorac-Jurcevic, T. et al. Proteomic analysis of chronic pancreatitis and pancreatic adenocarcinoma. Gastroenterology 129, 1454-1463 (2005).

38. Sun, H. C et al. Expression of hypoxia-inducible factor- 1 alpha and associated proteins in pancreatic ductal adenocarcinoma and their impact on prognosis. Int. J. Oncol. 30, 1359-1367 (2007).

39. Shibaji, T. et al. Prognostic significance of HIF-1 alpha overexpression in human pancreatic cancer. Anticancer Res. 23, 4721-4727 (2003).

40. Li, W. et al. Sphingosine kinase 1 is associated with gastric cancer progression and poor survival of patients. Clin. Cancer Res. 15, 1393-1399 (2009).

41. Fleming Martinez, A. K. \& Storz, P. Mimicking and manipulating pancreatic acinar-to-ductal metaplasia in 3-dimensional cell culture. J. Vis. Exp. 144, e59096 (2019).

42. Subramanian, A. et al. Gene set enrichment analysis: a knowledge-based approach for interpreting genome-wide expression profiles. Proc. Natl Acad. Sci. USA 102, 15545-15550 (2005).

43. Yu, G., Wang, L. G., Han, Y. \& He, Q. Y. clusterProfiler: an R package for comparing biological themes among gene clusters. OMICS 16, 284-287 (2012). 